\title{
CONSIDERAÇÕES SOBRE A FORMAÇÃO EM MEDICINA DE FAMÍLIA E ATENÇÃO PRIMÁRIA
}

\author{
COMMENTS ABOUT GRADUATE AND UNDERGRADUATE STUDIES ON \\ FAMILY MEDICINE AND PRIMARY HEALTHCARE
}

\begin{abstract}
Aldaisa C. Forster
Docente do Departamento de Medicina Social da Faculdade de Medicina de Ribeirão Preto - USP. Pós-doutorado junto à Coordenação da Unidad de Atención Primaria de la UAM.
\end{abstract}

Aproveito a oportunidade de estar desenvolvendo o projeto de investigação "O papel da especialidade de Medicina Familiar e Comunitária no ensino médico de graduação", sob a direção do Prof. Ángel Otero, em Madrid, para comentar, sucintamente, alguns aspectos de política sanitária e formação médica na Espanha, que, a principio, me parecem pertinentes, frente à realidade brasileira. O Prof. Otero buscou, em seu texto, ressaltar as influências externas que vêm demarcando o processo de incorporação da área de conhecimento de Medicina de Família e Atenção Primária na Universidade Espanhola, oriundas parte do Sistema Sanitário Espanhol e parte do contexto da União Européia.

A Espanha iniciou a Reforma Sanitária na década de 80, no marco da Reunião de Alma Ata (1978). Uma das metas era a transformação da estrutura de serviços públicos de saúde com a implantação, em todo o território nacional, de Centros de Atenção Primária e suas equipes, seguindo a orientação dos princípios da Atenção Primária à Saúde (AP): acessibilidade, Centros de AP como primeiro contato, continuidade da assistência, equipe assistencial com médico geral, corresponsabilização e participação comunitária.

Nessa época, era consenso, na maioria dos países desenvolvidos, que o médico geral precisava ter uma formação especial de pós-graduação em AP, mediante programas de especialidade em Medicina Geral ou Medicina de Família. Na Espanha, o programa da especialidade, Medicina de Familia y Comunitaria (MFYC), recém-criado, passou por aprimoramentos substanciais, principalmente no campo da prática. Simultaneamente, ocorreram reformulações no setor público de saúde espanhol, que contribuíram para a consolidação da especialidade como: a extensão da rede de centros de AP, a equipe assistencial de AP, compreendendo o médico de família, a constituição de unidades docentes do Insalud (Instituto Nacional de Salud), responsáveis pela formação e educação continuada em AP e MF.

Um estudo feito em 16 países íbero-americanos observou que o sucesso da medicina da família em cinco deles, entre os quais a Espanha, deveu-se à implantação abrangente da especialidade de médicos de família. O autor considerou que a reforma dos sistemas de serviços de saúde, realizada na América Latina, aplicou a AP como um elemento importante, porém, um conceito de AP sem vínculos com "os critérios de qualidade e formação dos recursos humanos" para a prestação dos serviços sanitários.

A meu ver, esses são alguns pontos do modelo sanitário espanhol que podem contribuir para a realidade brasileira. Aínda não houve consenso suficiente para interferir na política de saúde, na criação de uma nova especialidade e de um programa de formação de especialistas em nível nacional, que implique na melhoria da qualidade da assistência médica no país.

No que diz respeito à formação médica em AP e MF, pode-se afirmar que a universidade brasileira não a assumiu de forma ampla, todavía, percebe-se a tendência à implantação de novos currículos e de aproximação do ensino e aprendizagem da comunidade, na maioria das escolas médicas. Na Faculdade de Medicina de Ribeirão Preto - Universidade de São Paulo, com a reforma do currículo, surgiram as disciplinas "Estágio Integrado em Centros de Saúde" e "Medicina Comunitária I", ministradas à primeira turma de quintanistas da nova carreira em 1997. À semelhança da FM de la UAM, foi criada uma Unidada Docente de AP, que é o Centro de Atenção Primária 
e Saúde da Família, e está vinculado à faculdade. Com o apoio institucional do Hospital das Clínicas de Ribeirão Preto, criou-se o programa de residência médica em Medicina Geral e Comunitária, com ênfase no Programa de Saúde da Familia, de dois anos de duração, em 1999.

Esse processo vem crescendo em termos de adesão de instituições e do objeto de formação em saúde. Em período curto de tempo, foram criados os Núcleos Docentes de Saúde da Família e firmado um convênio entre a USP, por meio da Escola de Enfermagem de Ribeirão Preto e da FMRP, com a FM de São José de Rio Preto, a Secretaria de Estado da Saúde de São Paulo e a Secretaria Municipal de Saúde de Ribeirão Preto, estabelecendo-se o Pólo Norte-Oeste Paulista da Saúde da Família. Os núcleos e o pólo são instituições orientadas para a formação de pessoal e investigação em AP e Saúde da Família nos municípios pertencentes às regiões Norte e Oeste do Estado de São Paulo.
As atividades assistenciais e de formação em Atenção Primária e Saúde da Família vêm se incrementando no Brasil, mas é um processo com características heterogêneas.

À guisa de conclusão, reafirmo as palavras do Professor Ángel Otero, "el proceso de consolidación de la Medicina de Familia en la enseñanza de pregrado de la medicina es lento pero inevitable".

\section{BIBLIOGRAFÍA}

1 - CEITLIN J. Ser muchos es muy importante. Enseñanzas proporcionadas por la experiencia internacional en el desarrollo de la medicina familiar. Aten Primaria 24: 183-185, 1999. 